Check for updates

Cite this: Chem. Commun., 2017, 53,5531

Received 29th March 2017,

Accepted 24th April 2017

DOI: $10.1039 / c 7 c c 02419 c$

rsc.li/chemcomm

\section{Asymmetric fluorinative dearomatization of tryptamine derivatives $\dagger$}

\author{
Xiao-Wei Liang, Chuan Liu, Wei Zhang and Shu-Li You (D) *
}

\begin{abstract}
An asymmetric fluorinative dearomatization reaction of tryptamine derivatives was developed by using a chiral anion phase transfer catalyst (PTC) system, and the preliminary results of the reaction mechanistic study were achieved. This method is characterized by a simple operation, facile introduction of a fluorine atom in a highly enantioselective manner and construction of two contiguous quaternary stereogenic centers.
\end{abstract}

Fluorination reactions have witnessed tremendous development due to the extreme importance of fluorine-containing molecules in medicinal chemistry and materials science. ${ }^{1}$ Although catalytic asymmetric fluorination reactions have gained rapid growth accompanied by the emergence of catalytic systems, ${ }^{2}$ developing highly efficient stereoselective fluorination reactions is still in great demand. Catalytic asymmetric dearomatization (CADA) reactions have recently attracted enormous research interest due to their powerful ability to construct complex molecules from readily available aromatic compounds. ${ }^{3}$ Although CADA reactions through fluorination are undoubtedly attractive in the synthesis of chiral fluorine-containing compounds and highly desirable, successful reports are very limited in number. In 2011, Gouverneur and co-workers reported an elegant enantioselective dearomatization of indole derivatives via cascade fluorocyclization. In general, moderate to high levels of enantioselective control are obtained under catalytic conditions (Scheme 1). ${ }^{4}$ Almost at the same time, Toste and co-workers reported enantioselective electrophilic fluorination utilizing a chiral anion phase transfer catalyst. ${ }^{5}$ The examples of dearomatization of benzothiophenes reported therein elucidated the potential of CADA reactions via fluorination. Later, the same group further advanced the asymmetric fluorinative dearomatization reaction using phenols. ${ }^{6}$ Due to the great demand for complex chiral fluorinated molecules

State Key Laboratory of Organometallic Chemistry, Shanghai Institute of Organic Chemistry, Chinese Academy of Science, 345 Lingling Lu, Shanghai 200032, China. E-mail: slyou@sioc.ac.cn

$\dagger$ Electronic supplementary information (ESI) available. CCDC 1526408. For ESI and crystallographic data in CIF or other electronic format see DOI: $10.1039 / \mathrm{c} 7 \mathrm{cc} 02419 \mathrm{c}$ and our continuous interest in CADA reactions, herein, we report an asymmetric fluorinative dearomatization reaction of tryptamine derivatives, providing fluorine-containing pyrroloindolines bearing two contiguous quaternary stereogenic centers. Ma and co-workers had reported the chiral anion PTC strategy in bromination of tryptamine derivatives. Under the same catalytic conditions, the fluorination of 1a gave almost racemic results. ${ }^{7}$

We initiated our studies by examining the reaction of the tryptamine derivative 1a with Selectfluor ((1-(chloromethyl)4-fluoro-1,4-diazoniabicyclo[2.2.2]octane)) (1.1 equiv.), in the presence of $(S)$-TRIP $((S)$-3,3'-bis(2,4,6-triisopropylphenyl)-1,1'binaphthyl-2,2'-diyl hydrogen phosphate) (10 mol\%) and sodium carbonate (1.1 equiv.) in fluorobenzene (Table 1 , entry 1$)$. The fluorocyclization product 2a was given in $48 \%$ yield and $6 \%$ ee.

Encouraged by these results, various chiral phosphoric acids (CPAs) (10 mol\%) were evaluated. ${ }^{8}$ Although all reactions proceeded

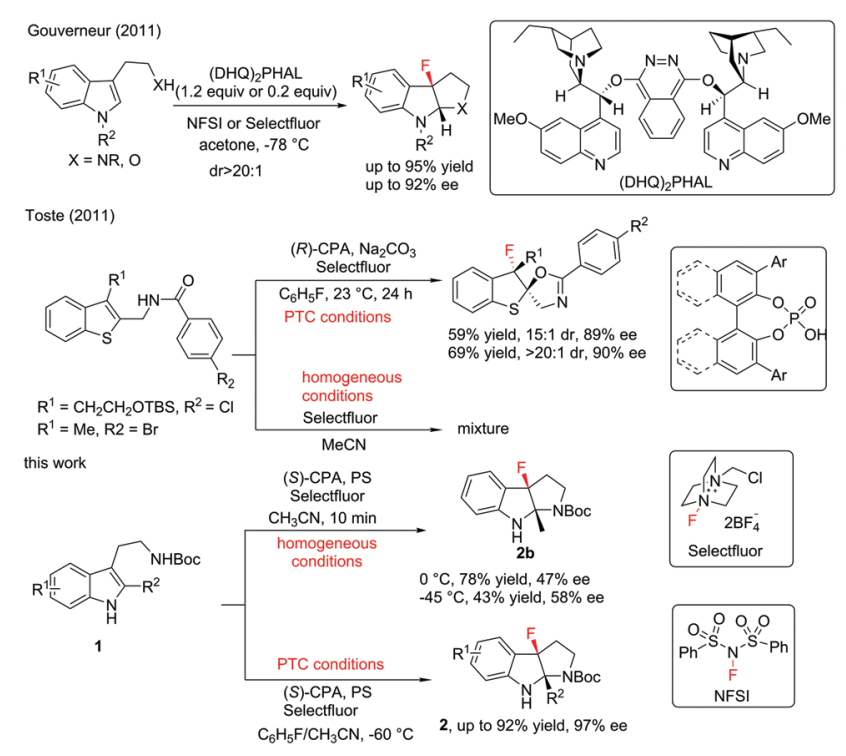

Scheme 1 Enantioselective fluorinative dearomatization reactions of tryptamine derivatives. 
Table 1 Evaluation of chiral phosphoric acids

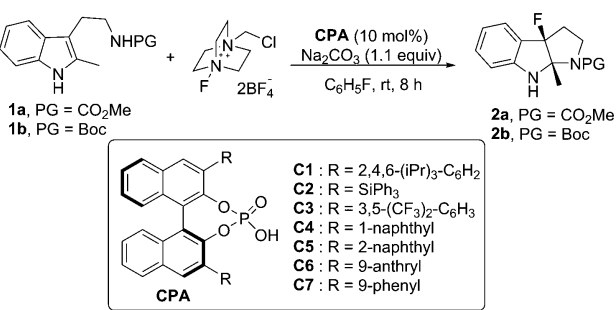

\begin{tabular}{llllc}
\hline Entry $^{a}$ & CPA & 1 & Yield $^{b}(\%)$ & $\mathrm{ee}^{c}(\%)$ \\
\hline 1 & C1 & 1a & 48 & 6 \\
2 & C2 & 1a & 70 & 4 \\
3 & C3 & 1a & 52 & 0 \\
4 & C4 & 1a & 58 & 13 \\
5 & C5 & 1a & 48 & 3 \\
6 & C6 & 1a & 67 & 37 \\
7 & C7 & 1a & 56 & 22 \\
8 & C6 & 1b & 48 & 55
\end{tabular}

${ }^{a}$ Reactions were performed with $1(0.2 \mathrm{mmol})$, Selectfluor $(0.22 \mathrm{mmol})$, $\mathrm{Na}_{2} \mathrm{CO}_{3}(0.22 \mathrm{mmol}), \mathbf{C P A}(0.02 \mathrm{mmol})$ in $\mathrm{C}_{6} \mathrm{H}_{5} \mathrm{~F}(4 \mathrm{~mL})$ at rt. ${ }^{b}$ Isolated yield. ${ }^{c}$ Determined by HPLC analysis.

to afford the desired fluorinated $6 H$-pyrroloindole ${ }^{9} \mathbf{2 a}$, only moderate yields could be achieved and the enantioselective control was not satisfactory (Table 1 , entries 1 to 7 ). Among all the CPAs surveyed, C6 was the optimal one to give 2a in $67 \%$ yield with $37 \%$ ee (Table 1 , entry 6 ). To our delight, when the protecting group of tryptamine derivative 1 was switched from $\mathrm{CO}_{2} \mathrm{Me}(\mathbf{1 a})$ to Boc $(\mathbf{1 b})$, product $2 \mathrm{~b}$ was obtained in $55 \%$ ee (Table 1 , entry 7 ).

With $\mathbf{1 b}$ as the model substrate, several commonly used nonpolar solvents were first screened, and fluorobenzene proved to be the optimal one ( $48 \%$ yield, $55 \%$ ee). Due to the importance of a base for the anionic chiral phase-transfer catalysis, both inorganic and organic bases were examined, and proton sponge (PS) was found to be efficient to increase the yield (Table 2, entry 2). When the reaction temperature was decreased from rt to $0{ }^{\circ} \mathrm{C}$, the reaction proceeded smoothly with increased enantioselectivity ( $56 \%$ to $65 \%$ ee) but a prolonged reaction time was needed (Table 2, entry 3). However, the addition of $4 \AA$ molecular sieves (MS) led to a complicated reaction mixture with a decreased yield and enantioselective control (Table 2, entry 4).

Different from the phenomena where substrates treated with Selectfluor under homogeneous conditions were converted to a complex mixture in the chiral anion phase-transfer catalytic system, ${ }^{4,5}$ screening polar solvents as homogeneous conditions for this reaction afforded positive results (see the ESI $\dagger$ for details). Among those tested, acetonitrile was the most optimal to provide 2b in $78 \%$ yield; however, the enantioselectivity was decreased slightly (Table 2, entry 5). These results encouraged us to test mixed solvents. When mixed solvents of fluorobenzene and acetonitrile $(1: 1)$ were utilized, the desired product $2 \mathbf{b}$ was obtained in 50\% yield and 69\% ee within $10 \mathrm{~min}$ (Table 2, entry 6). Further decreasing the reaction temperature to $-60{ }^{\circ} \mathrm{C}$ afforded $2 \mathbf{b}$ in $64 \%$ yield with $90 \%$ ee (Table 2 , entry 7 ). To our delight, running the reaction in a higher concentration improved the yield to a satisfactory level (87\% yield) (Table 2, entry 8). Notably,
Table 2 Evaluation of reaction parameters

\begin{tabular}{|c|c|c|c|c|c|}
\hline & $1 \mathrm{~b}$ & 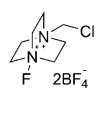 & $\begin{array}{c}\text { C6 (10 mol\%) } \\
\text { PS ( } 1.1 \text { equiv) } \\
\text { solvent }\end{array}$ & $\widehat{P}_{\mathrm{NBOC}}$ & \\
\hline entry ${ }^{a}$ & Solvent & Time & Temp. $\left({ }^{\circ} \mathrm{C}\right)$ & Yield $^{b}(\%)$ & $\mathrm{ee}^{c}(\%)$ \\
\hline & $\mathrm{C}_{6} \mathrm{H}_{5} \mathrm{~F}$ & $8 \mathrm{~h}$ & $\mathrm{rt}$ & 48 & 55 \\
\hline & $\mathrm{C}_{6} \mathrm{H}_{5} \mathrm{~F}$ & $8 \mathrm{~h}$ & $\mathrm{rt}$ & 72 & 56 \\
\hline & $\mathrm{C}_{6} \mathrm{H}_{5} \mathrm{~F}$ & $16 \mathrm{~h}$ & 0 & 60 & 65 \\
\hline$e^{e}$ & $\mathrm{C}_{6} \mathrm{H}_{5} \mathrm{~F}$ & $11 \mathrm{~h}$ & 0 & 41 & 5 \\
\hline & $\mathrm{CH}_{3} \mathrm{CN}$ & $10 \mathrm{~min}$ & 0 & 78 & 47 \\
\hline & $\mathrm{C}_{6} \mathrm{H}_{5} \mathrm{~F} / \mathrm{CH}_{3} \mathrm{CN}$ & $10 \mathrm{~min}$ & 0 & 50 & 69 \\
\hline & $\mathrm{C}_{6} \mathrm{H}_{5} \mathrm{~F} / \mathrm{CH}_{3} \mathrm{CN}$ & $16 \mathrm{~h}$ & -60 & 64 & 90 \\
\hline$f$ & $\mathrm{C}_{6} \mathrm{H}_{5} \mathrm{~F} / \mathrm{CH}_{3} \mathrm{CN}$ & $16 \mathrm{~h}$ & -60 & 87 & 90 \\
\hline q $f$ & $\mathrm{C}_{6} \mathrm{H}_{5} \mathrm{~F} / \mathrm{CH}_{3} \mathrm{CN}$ & $18 \mathrm{~h}$ & -60 & 66 & 90 \\
\hline $10^{d}$ & $\mathrm{C}_{6} \mathrm{H}_{5} \mathrm{~F} / \mathrm{CH}_{3} \mathrm{CN}$ & $18 \mathrm{~h}$ & -60 & 71 & 60 \\
\hline
\end{tabular}

${ }^{a}$ Reaction conditions: $1 \mathbf{b}(0.2 \mathrm{mmol})$, C6 $(0.02 \mathrm{mmol})$, Selectfluor $(0.22 \mathrm{mmol}), \mathrm{PS}(0.22 \mathrm{mmol})$ in solvent $(4 \mathrm{~mL}) .{ }^{b}$ Isolated yield. ${ }^{c}$ Determined by HPLC analysis. ${ }^{d} \mathrm{Na}_{2} \mathrm{CO}_{3}$ instead of PS. ${ }^{e} 4$ A MS was used. ${ }^{f} \mathrm{C}_{6} \mathrm{H}_{5} \mathrm{~F} / \mathrm{CH}_{3} \mathrm{CN}(1: 1,2 \mathrm{~mL}) .{ }^{g} 5 \mathrm{~mol} \%$ C6. PS: proton sponge.

5 mol\% catalyst loading gave the same enantioselectivity ( $90 \%$ ee) and $66 \%$ yield (Table 2, entry 9 ).

With the optimal reaction conditions in hand (Table 2, entry 8), the substrate scope was explored to test the generality of this asymmetric fluorinative dearomatization reaction. Firstly, the protecting group of the tryptamine was evaluated. As shown in Table 3, in general, all the substrates with electron-withdrawing protecting groups $\left(\mathrm{CO}_{2} \mathrm{Me}\right.$, Boc, Fmoc and $\left.\mathrm{Cbz}\right)$ were converted to their corresponding fluorinative dearomatization products with satisfactory enantioselectivity (85-90\% ee, 2a to 2 d) and moderate to good yields. The substituents on the indole moiety were further explored. N-Boc protected tryptamines with varied electron-donating substituents $\left(5-\mathrm{CH}_{3}, 5-\mathrm{MeO}, 5-t \mathrm{Bu}\right)$ at the C5 position were well tolerated to provide their corresponding products with good enantioselectivity (82-90\% ee) and 50-64\% yields ( $2 \mathrm{e}$ to $\mathbf{2 g}$ ), and a methyl group at the $\mathrm{C} 7$ position led to only moderate enantioselectivity $(61 \%$ ee) due to the steric hindrance effect (2h). The electron-withdrawing substituent (5-F, 5- Cl, 5- Br, 5- $\mathrm{CF}_{3}$ and $\left.5-\mathrm{CO}_{2} \mathrm{Et}\right)$ at the $\mathrm{C} 5$ position of the indole moiety was also well tolerated to provide the target compounds with good enantioselectivity (85-89\% ee) and $29-89 \%$ yields ( $2 \mathbf{i}$ to $2 \mathbf{m}$ ). Substrates bearing a $\mathrm{Br}$ substituent at the different positions $(4,5,6,7)$ of the indole core underwent dearomatization smoothly (84-92\% yields) but with varied enantioselectivity (64-97\% ee). Notably, a 6-Br product was obtained in 97\% ee (2o). Interestingly, the reactions of 4,6-dihalo-substituted substrates proceeded with excellent enantioselectivity ( $96 \%$ ee, 2q, 2r). Finally, the 2-substituent of the indole moiety was evaluated, and a good enantioselectivity (85-89\% ee) was obtained for substrates bearing simple alkyl (2s), cyclopropyl (2t), and alkenyl functional groups (2u). The reaction conditions were also compatible with substrates bearing more hindered substituents or simple $\mathrm{H}$ with slightly dropped enantioselectivity $(2 \mathbf{v}, 2 \mathbf{w}, 2 \mathbf{x}$, 51-68\% yields, 56-77\% ee).

Interestingly, the reaction of 3,5-dimethyl substituted substrate 1y under the optimal reaction conditions led to the isolation of 2yy in $72 \%$ yield and $93 \%$ ee. It is likely that the dearomatized 
Table 3 Substrate scope ${ }^{a}$

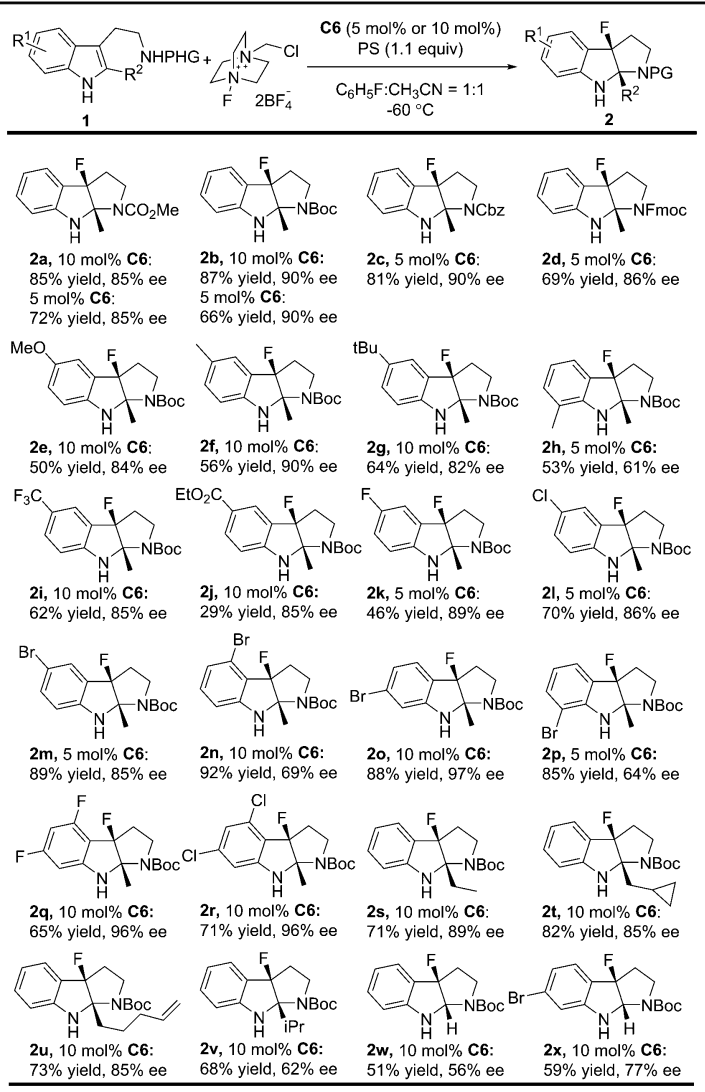

${ }^{a}$ Reaction conditions: 1 (0.2 mmol), C6 (0.02 mmol), Selectfluor $(0.22 \mathrm{mmol})$, base $(0.22 \mathrm{mmol})$ in $\mathrm{C}_{6} \mathrm{H}_{5} \mathrm{~F}: \mathrm{CH}_{3} \mathrm{CN}(1: 1,2 \mathrm{~mL})$ at $-60{ }^{\circ} \mathrm{C}$. Isolated yield. ee was determined by HPLC analysis.

intermediate $2 \mathbf{y}$ is unstable due to the introduction of three methyl groups on the indole ring, which facilitates the C-F bond cleavage to result in the formation of a stable benzyl carbenium (Scheme 2).

The reaction of $\mathbf{1 b}$ in the gram-scale proceeded well affording the dearomative product $\mathbf{2 b}$ in $\mathbf{7 9} \%$ yield and $86 \%$ ee (Scheme 3). Furthermore, the protection reaction of $\mathrm{N}-\mathrm{H}$ in $\mathbf{2 b}$ with trifluoroacetic anhydride was carried out to give 4 in $88 \%$ yield, and the Boc group in 3 could be removed by TMSOTf at $-78{ }^{\circ} \mathrm{C}$ (Scheme 4). X-Ray crystallography analysis of a single crystal of enantiopure 3 revealed its absolute configuration as $3 a R, 8 a S$. Treatment of $\mathbf{1 b}$ with NBS and 1,3,5-trichloroisocyanuric acid (TCCA) led to the dibromo compound $\mathbf{2 b b}$ (68\% yield, $86 \%$ ee) together with $32 \%$ yield of the monobromo compound $\mathbf{2 p}$, and the dichloro compound 2 be (66\% yield, $86 \%$ ee), respectively.

To shed light on the reaction mechanism, control experiments were carried out to examine the effects of acid and base

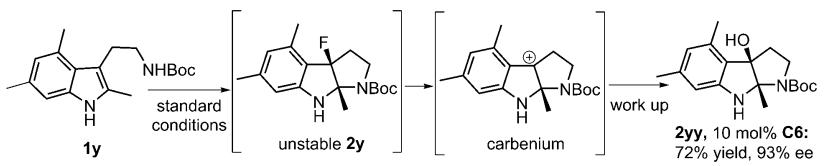

Scheme 2 The fluorinative dearomatization reaction of $\mathbf{1 y}$ and hydrolysis.

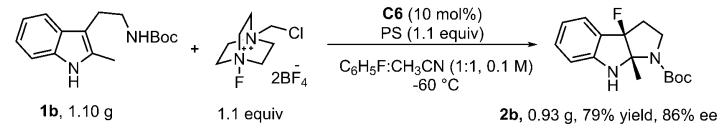

Scheme 3 Gram-scale reaction.

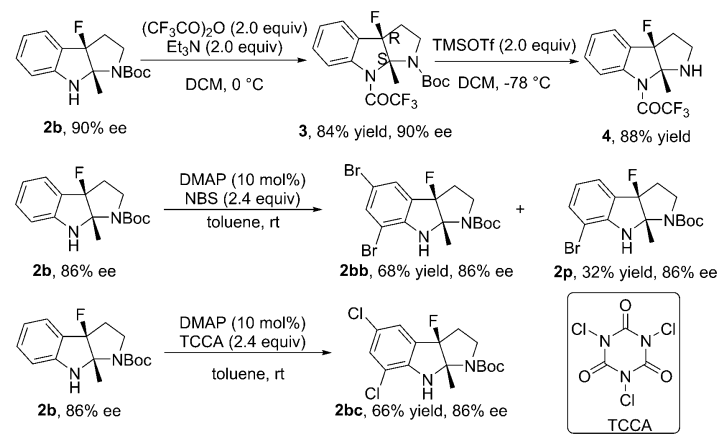

Scheme 4 Transformations of product $\mathbf{2 b}$

additives to the reaction outcomes. The correlation between conversion of $\mathbf{1 b}$ with reaction time under varied reaction conditions is shown in Fig. 1. Notably, a strong background reaction was observed. The rate of the reaction of $\mathbf{1} \mathbf{b}$ without a chiral phosphoric acid catalyst or PS was similar to that under the standard conditions (entry 8, Table 2). We envisioned that $\mathrm{HBF}_{4}$ released from Selectfluor might accelerate the reaction. Indeed, when 1 equiv. of $\mathrm{HBF}_{4}$ was added, the reaction becomes even faster while the reaction becomes sluggish when 1.2 equiv. of PS was employed. These data imply that the role of PS in this reaction is to neutralize $\mathrm{HBF}_{4}$ generated in situ and hence inhibit the racemic background reaction.

In conclusion, an asymmetric fluorinative dearomatization reaction of tryptamine derivatives was developed based on a chiral anion phase transfer strategy. The preliminary investigations on the reaction mechanism suggested that the reaction proceeds via bifunctional activation by a chiral BINOL-derived phosphate anion. This method is characterized by simple operation, facile introduction of a fluorine atom in a highly enantioselective manner and construction of two contiguous quaternary stereogenic centers.

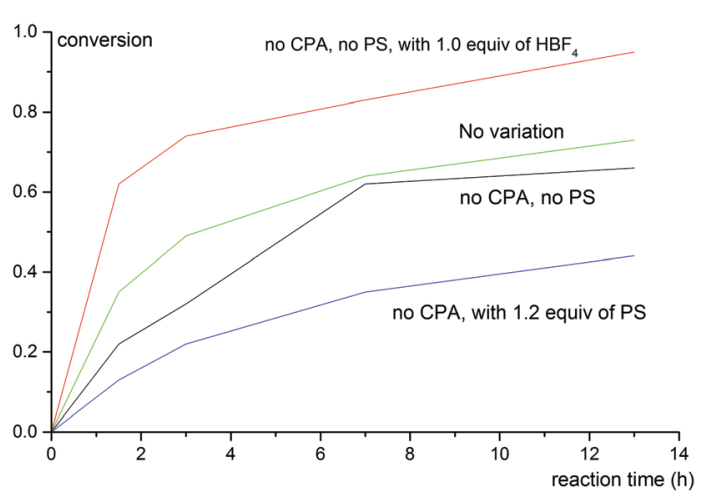

Fig. 1 Correlation between conversion of $\mathbf{1 b}$ with reaction time under varied reaction conditions. The variation from the "standard reaction conditions" (entry 8, Table 2) is denoted for each plot. 
We thank the National Key Research and Development Program of China (2016YFA0202900), the National Basic Research Program of China (2015CB856600), NSFC (21332009, 21361140373, and 21421091), and the Chinese Academy of Sciences (XDB20000000, QYZDY-SSW-SLH012) for generous financial support.

\section{Notes and references}

1 (a) K. Müller, C. Faeh and F. Diederich, Science, 2007, 317, 1881; (b) I. Ojima, Fluorine in Medicinal Chemistry and Chemical Biology, Wiley-Blackwell, Oxford, UK, 2009; (c) V. Gouverneur and K. Müller, Fluorine in Pharmaceutical and Medicinal Chemistry: From Biophysical Aspects to Clinical Applications, Imperial College Press, London, 2012; (d) P. Kirsch, Modern Fluoroorganic Chemistry: Synthesis, Reactivity, Applications, Wiley-VCH, Weinheim, Germany, 2nd edn, 2013.

2 For recent reviews on catalytic asymmetric fluorination reactions, see: (a) M. C. Pacheco, S. Purser and V. Gouverneur, Chem. Rev., 2008, 108, 1943; (b) J. R. Wolstenhulme and V. Gouverneur, Acc. Chem. Res., 2014, 47, 3560; (c) J. Wu, Tetrahedron Lett., 2014, 55, 4289; (d) X. Yang, T. Wu, R. J. Phipps and F. D. Toste, Chem. Rev., 2015, 115, 826; (e) T. Sugiishi, M. Matsugi, H. Hamamotob and H. Amii, RSC Adv., 2015, 5, 17269; $(f)$ P. A. Champagne, J. Desroches, J.-D. Hamel, M. Vandamme and J.-F. Paquin, Chem. Rev., 2015, 115, 9073.

3 For recent reviews on dearomatization reactions, see: $(a)$ A. R. Pape, K. P. Kaliappan and E. P. Kündig, Chem. Rev., 2000, 100, 2917; (b) A. Pelter and R. S. Ward, Tetrahedron, 2001, 57, 273; (c) E. P. Kündig and A. Pape, Top. Organomet. Chem., 2004, 7, 71; (d) W. D. Harman, Top. Organomet. Chem., 2004, 7, 95; (e) S. Quideau, L. Pouységu and D. Deffieux, Curr. Org. Chem., 2004, 8, 113; $(f)$ F. López Ortiz, M. J. Iglesias, I. Fernández, C. M. Andújar Sánchez and G. R. Gómez, Chem. Rev., 2007, 107, 1580; $(g)$ S. Quideau, L. Pouységu and D. Deffieux, Synlett, 2008, 467; (h) L. Pouységu, D. Deffieux and S. Quideau, Tetrahedron, 2010, 66, 2235; (i) C.-X. Zhuo, W. Zhang and S.-L. You, Angew. Chem., Int. Ed., 2012, 51, 12662; ( j) C.-X. Zhuo, C. Zheng and S.-L. You, Acc. Chem. Res., 2014, 47, 2558; ( $k$ ) Q. Ding, X. Zhou and R. Fan, Org. Biomol. Chem., 2014, 12, 4807; (l) W.-T. Wu, L. Zhang and S.-L. You, Chem. Soc. Rev., 2016, 45, 1570; ( $m$ ) W. Sun, G. Li, L. Hong and R. Wang, Org. Biomol. Chem., 2016, 14, 2164; (n) X.-W. Liang, C. Zheng and S.-L. You, Chem. - Eur. J., 2016, 22, 11918; (o) C. Zheng and S.-L. You, Chem, 2016, 1, 857.

4 (a) O. Lozano, G. Blessley, T. M. del Campo, A. L. Thompson, G. T. Giuffredi, M. Bettati, M. Walker, R. Borman and V. Gouverneur, Angew. Chem., Int. Ed., 2011, 50, 8105. For other examples of fluorinative dearomatization of tryptamine derivatives, see: $(b)$ N. Shibata, T. Tarui, Y. Doi and K. L. Kirk, Angew. Chem., Int. Ed., 2001, 40, 4461; (c) T. Fujiwara, T. Seki, T. Yakura and Y. Takeuchi, J. Fluorine Chem., 2014, 165, 7.
5 (a) V. Rauniyar, A. D. Lackner, G. L. Hamilton and F. D. Toste, Science, 2011, 334, 1681. For reviews on anionic chiral PTC strategy, see:; (b) R. J. Phipps, G. L. Hamilton and F. D. Toste, Nat. Chem., 2012, 4, 603; (c) M. Mahlau and B. List, Angew. Chem., Int. Ed., 2013, 52, 518; (d) K. Brak and E. N. Jacobsen, Angew. Chem., Int. Ed., 2013, 52, 534. 6 (a) R. J. Phipps and F. D. Toste, J. Am. Chem. Soc., 2013, 135, 1268. For leading examples using the anionic chiral PTC strategy, see: (b) R. J. Phipps, K. Hiramatsu and F. D. Toste, J. Am. Chem. Soc., 2012, 134, 8376; (c) Y.-M. Wang, J. Wu, C. Hoong, V. Rauniyar and F. D. Toste, J. Am. Chem. Soc., 2012, 134, 12928; (d) T. Honjo, R. J. Phipps, V. Rauniyar and F. D. Toste, Angew. Chem., Int. Ed., 2012, 51, 9684; (e) H. P. Shunatona, N. Früh, Y.-M. Wang, V. Rauniyar and F. D. Toste, Angew. Chem., Int. Ed,, 2013, 52, 7724; $(f)$ A. J. Neel, J. P. Hehn, P. F. Tripet and F. D. Toste, J. Am. Chem. Soc., 2013, 135, 14044; $(g)$ J. Wu, Y.-M. Wang, A. Drljevic, V. Rauniyar, R. J. Phipps and F. D. Toste, Proc. Natl. Acad. Sci. U. S. A., 2013, 110, 13729; (h) A. D. Lackner, A. V. Samant and F. D. Toste, J. Am. Chem. Soc., 2013, 135, 14090.

7 For asymmetric brominative dearomatization reactions of tryptamines, see: (a) W. Xie, G. Jiang, H. Liu, J. Hu, X. Pan, H. Zhang, X. Wan, Y. Lai and D. Ma, Angew. Chem., Int. Ed., 2013, 52, 12924; (b) X. Feng, G. Jiang, Z. Xia, J. Hu, X. Wan, J.-M. Gao, Y. Lai and W. Xie, Org. Lett., 2015, 17, 4428. Notably, the asymmetric fluorination of tryptamine derivative 1a under the same catalytic conditions only gave moderate yield and almost racemic result ( $45 \%$ yield, $5 \%$ ee).

8 For selected reviews on chiral phosphoric acid catalysis, see: (a) T. Akiyama, Chem. Rev., 2007, 107, 5744; (b) M. Terada, Synthesis, 2010, 1929; (c) J. Yu, F. Shi and L.-Z. Gong, Acc. Chem. Res., 2011, 44, 1156; (d) M. Rueping, A. Kuenkel and I. Atodiresei, Chem. Soc. Rev., 2011, 40, 4539; (e) D. Parmar, E. Sugiono, S. Raja and M. Rueping, Chem. Rev., 2014, 114, 9047, For pioneering contributions, see: $(f)$ D. Uraguchi and M. Terada, J. Am. Chem. Soc., 2004, 126, 5356; $(g)$ T. Akiyama, J. Itoh, K. Yokota and K. Fuchibe, Angew. Chem., Int. Ed., 2004, 43, 1566.

9 For selected examples of CADA reactions of indoles, see: (a) Q.-F. Wu, H. He, W.-B. Liu and S.-L. You, J. Am. Chem. Soc., 2010, 132, 11418; (b) Q.-F. Wu, C. Zheng and S.-L. You, Angew. Chem., Int. Ed., 2012, 51, 1680; (c) Q. Yin and S.-L. You, Org. Lett., 2013, 15, 4266; (d) Q. Yin and S.-L. You, Org. Lett., 2014, 16, 2426; (e) Q. Cai, Q. Yin and S.-L. You, Asian J. Org. Chem., 2014, 3, 408; $(f)$ D. Duan, Q. Yin, S. Wang, Q. Gu and S. You, Acta Chim. Sin., 2014, 72, 1001; $(g)$ W. Shao, H. Li, C. Liu, D.-J. Liu and S.-L. You, Angew. Chem., Int. Ed., 2015, 54, 7684; (h) C.-X. Zhuo, Y. Zhou, Q. Cheng, L. Huang and S.-L. You, Angew. Chem., Int. Ed., 2015, 54, 14146; (i) X. Zhang, W.-B. Liu, H.-F. Tu and S.-L. You, Chem. Sci., 2015, 6, 4525; $(j)$ L. Han, W. Zhang, X.-X. Shi and S.-L. You, Adv. Synth. Catal., 2015, 357, 3064; (k) C. Liu, J.-C. Yi, Z.-B. Zheng, Y. Tang, L.-X. Dai and S.-L. You, Angew. Chem., Int. Ed, 2016, 55, 751; (l) R.-D. Gao, Q.-L. Xu, B. Zhang, Y. Gu and S.-L. You, Chem. - Eur. J., 2016, 22, 11601. 